\title{
El papel de los intelectuales en la gestación de la II República Española. Intelectuales socialistas: trayectoria y actuación para la consecución del triunfo electoral del PSOE en el primer Bienio Republicano
}

\author{
María Cruz Galindo \\ Universidad Politécnica de Madrid
}

The role of the intelectuals in the origins of the Second Spanish Republic. Socialist intelectuals' evolution and actuation for gettin the electoral triumph of the PSOE at te First Two Years of Republican Government

\begin{abstract}
RESUMEN
La II República Española ha sido uno de los acontecimientos de mayor relevancia del siglo xx por las consecuencias políticas, sociales y económicas que trajo consigo y que estuvieron siempre orientadas al cambio y modernización de España. El proyecto republicano que se inauguró en 1931 fue la culminación de toda una serie de anhelos que venían gestándose desde mucho tiempo atrás por parte de distintos grupos políticos $y$ sociales, pero también por parte de un importante sector cultural: los intelectuales, quienes desempeñaron una labor decisiva en la gestación y configuración de la II República, hasta tal punto que, en no pocas ocasiones, este régimen ha sido denominado como la «república de los intelectuales». La comunicación «El papel de los intelectuales en la gestación de la II

República Española. Intelectuales socialistas: trayectoria y actuación para la
\end{abstract}

\section{ABSTRACT}

The Spanish Second Republic has been one of the most relevant events of the $X X$ th century because of the political, social and economic consequences which it brought and that were always thought to the change and modernization of Spain. The republican project that was opened in 1931 was the end of a series of wishes that were developing for a long time by different political and social groups, but also by an important cultural sector: the intelectuals, who carried out a decisive task in the preparation and configuration of the Second Republic, so that on several occasions this regime has been named as the «Intelectuals' Republic».

The communication "The role of the intelectuals in the origins of the Second Spanish Republic. Socialist intelectuals' evolution and actuation for getting the electoral triumph of the PSOE at the First Two Years of Republican Government" wants to analise two main aspects. On the 
consecución del triunfo electoral del PSOE en el primer Bienio Republicano» quiere analizar dos aspectos principales. De una parte, y teniendo en cuenta que el nuevo régimen de 1931 estuvo formado por 258 profesionales de formación intelectual (profesores, farmacéuticos, abogados, etc.), pretendo una aproximación al origen de la participación de dicho sector social en la vida política española, sus primeras incursiones como grupo de poder relevante y sus diferentes simpatías y trayectorias políticas. Todos estos aspectos, tal y como ser verá, fueron claves a la hora de determinar los diferentes «programas» políticos, sociales

y económicos que cada uno de estos intelectuales en particular, o bien como grupo, presentaron como solución para alcanzar el más moderno de los regímenes europeos.

De otra parte, el segundo objetivo de la comunicación es el análisis de los intelectuales socialistas. El papel que el PSOE desempeñó en la consecución del nuevo régimen republicano y en la configuración del mismo fue decisivo, teniendo como principales protagonistas a un sector que comenzó a alcanzar su mayor apogeo en los años de la Dictadura de Primo de Rivera: los intelectuales. No es exagerado afirmar que los intelectuales socialistas desempeñaron una función clave en dos ámbitos principales: el de configuración del Partido Socialista que, gracias a su nuevo bagaje, pudo llegar al poder, y el de diseño de un régimen político que pretendía recoger las propuestas políticas, sociales y económicas más modernas que hasta entonces había tenido la Historia política de España. Sin embargo, la labor que en su día hubieron de desempeñar los intelectuales socialistas, incluso dentro de su propio Partido, no fue siempre fácil ni bien acogida: previa a la llegada de la II

República, e incluso durante el mismo régimen, hubo que preparar a las bases socialistas y a muchos de sus dirigentes para que aceptaran a un sector que hasta el momento se había considerado como opuesto a los conceptos del partido. Pero hubo también que defender, explicar y one hand, and considering that the new regime of 1931 was formed by 258 professionals of intelectual preparation (teachers, chemists, lawyers, etc.) I claim an approach to the origin of the participation of this social sector in the Spanish political life, their first actings as an important power group, and their different ideas and political ways. All these aspects, as it will be explained, were very important for determining the different social, political and economic programs that every one of these intelectuals in an individual way, or as a group, presented as a solution for getting the most modern of the European Regimes.

On the other hand, the second target of the communication is the analysis of the socialist intelectuals. The role that the PSOE had in getting the new republican regime and in its configuration was decisive, having as main protagonists a sector that began to get their climax during the Primo de Rivera Dictatorship: the intelectuals.

It is not exaggerated to say that the socialist intelectuals had a decisive function in two main áreas: in the configuration of the Socialist Party that, thanks to its new characteristics, could get the power; and in the design of a political regime that claimed to take the most modern political, social and economic proposals that the Spanish History had ever had. Nevertheless, the task that one day had to do the socialist intelectuals, even in their own party, was not always easy or well accepted: before the arrival of the Second Republic, and even during the same regime, it was necessary to prepare the socialist population and many of its leaders for getting them to accept a sector that so far had been considered as oppossed to the party concepts. But it was also necessary to defend, explain and justify many of the decitions that the socialist intelectuals were adopting as the new Government went on, measures as the colaboration with the Republicans, the definition of the Socialist political target (Democratic Govemmet versus Socialist Government), etc.

So the Second Republic Regime had in its 
justificar muchas de las decisiones que los intelectuales socialistas iban adoptando a medida que avanzaba el nuevo Gobierno, medidas como la colaboración con los republicanos, la definición del objetivo político socialista (gobierno democrático versus gobierno socialista) etc.

Por tanto, el Régimen de la II República contó con una gestación y en su definición final con la intervención decisiva de un nuevo grupo social que, de forma compacta (aunque no homogénea), comenzó desde principios del siglo xx a intervenir en el mundo de la política para llegar a convertirse en un grupo de poder en 1931: los intelectuales. Y junto con todas las generaciones, procedencias pedagógicas y culturales que en 1931 se dieron cita en el nuevo Gobierno

Republicano, los intelectuales socialistas fueron los que tuvieron que realizar paralelamente una labor de definición interna que resultó decisiva para el Partido y para muchos de los elementos claves con los que se conformó el nuevo régimen republicano.

PALABRAS CLAVE: Intelectuales, Profesionales, Grupo de poder, Programas políticos, sociales y económicos, PSOE, Bases socialistas. formation and final definition the decisive actuation of a new social group that, in a compact way (although not in a homogeneous one), began since the beginnings of the $X X$ th century to participate in the political world for becoming a power group in 1931: the intelectuals. And with all the generations, pedagogic and cultural origins that in 1931 were the new Republic Government, the socialists intelectuals were those who had to make at the same time an important job of internal definition which was decisive for the Party and for many of the main items with which the new Republic Regime was formed.

\section{KEYWORDS:}

Intelectuals, Professionals, Lobby, Politic, social and economic targets, Spanish Socialist Worker Party, Socialist supporters.

La presencia de grupos intelectuales en la sociedad ha sido una constante en la Historia de España, aunque su influencia real y decisiva en ámbitos como la política, la educación, la religión, etc., con unas consecuencias verdaderamente relevantes no se produjo hasta finales del siglo XIX y, de forma mucho más radical, en el xx. Estoy refiriéndome a la participación del intelectual en unos marcos de actuación que sobrepasan con mucho el que tradicionalmente les ha sido asignado de mediadores culturales e ideológicos, o referentes morales. A partir de principios del sigo xx el intelectual se incorporó a un mundo donde creyó que podía llevar a la práctica todo su «mundo de las ideas»: la política.

La presencia de estos grupos rectores en dicho ámbito durante la II República Española tuvo sus orígenes en la toma de conciencia que se produjo, a finales del siglo XIX, de la necesidad de reformar España a través de unos parámetros que excedían la mera influencia cultural que los intelectuales podían proporcionar a través del tradicional ejercicio de su profesión. Según Manuel Cortina, «La derrota militar (del 98) afectó a algunos intelectuales provocando una actitud de resistencia ante 
las instituciones. De ella arranca la crisis del Estado que décadas más tarde llevaría al advenimiento de la ll República en 1931»1.

Es a partir de ese momento, en que una derrota militar actuó como detonante de una crisis política, social y económica que venía anunciándose desde hacía mucho tiempo, cuando en España comenzaron los intelectuales a decidir su participación directa en la política. Si el Krausismo y sus herederos de la ILE propugnaron la evolución de la sociedad a través de la intervención de instituciones principalmente educativas ${ }^{2}$, sus continuadores fueron partidarios de medidas mucho más drásticas o pragmáticas. Las denominadas Generaciones del 14 y del 27, de donde provenían figuras de la relevancia de Ortega y Gasset, Marañón, Azaña, Antonio Machado..., se decantaron por la participación política para conseguir, de esta manera, la tan necesaria reforma. Ambos grupos fueron rebeldes con lo establecido ya fuese político, cultural o social.

Políticamente, el Liberalismo en España venía asimilándose con posturas ideológicamente muy próximas al republicanismo y la izquierda, pero sin admitir tácticas violentas y siendo posible su desarrollo dentro del sistema dinástico. Fueron las generaciones de intelectuales que podrían asimilarse a las del 14 y 27 las que, en general, se opusieron radicalmente a la Monarquía sin aceptar la continuidad de una nueva opción política dentro de este mismo régimen. Mantuvieron posturas aliadófilas y defendieron, como es el caso de Ortega, la «revolución desde arriba» para que «habiendo negado una España, nos encontremos en el paso honroso de encontrar otra» ${ }^{3}$. Como señala Tuñón de Lara, fueron víctimas de su propia profesión; no supieron establecer un límite a la búsqueda de la verdad convirtiéndose en víctimas de un ambiente absolutamente politizado. Sus principios políticos eran herencia ineludible de los movimientos socio-culturales de períodos anteriores: el pedagogismo, la secularización, el reformismo político y social... llevaban la impronta del Krausismo y de la ILE ${ }^{4}$.

Culturalmente eran generaciones tremendamente preparadas y especializadas a través de la Universidad, teniendo en muchos casos contactos directos con culturas extranjeras gracias a estancias en distintos países. Eran seguidores de la cultura alemana (caso de Ortega), la británica (la ILE), o la francesa, y todo su deseo de europeizar la sociedad española lo llevaron a cabo a través de instituciones como el Ateneo o la Residencia de Estudiantes, donde se formaron y desde donde

1 SuÁrez Cortina, Manuel, El reformismo en España, Madrid, Ed. Siglo XXI, 1986, Pág. 1.

$2 \mathrm{M}^{\text {a }}$ Dolores Gómez Molleda considera que tanto el Krausismo como la ILE mantuvieron siempre como principio fundamental de su existencia la reforma de España a través de la proyección natural de sus instituciones pedagógicas y educativas sobre la sociedad. De esta forma se lograría la transformación gradual de los individuos y, consiguientemente, de las estructuras sociales. Sin embargo, el Krausismo, identificado políticamente con el republicanismo, si influyó sobre los políticos más liberales de la época, no se asimiló con ellos. Intelectuales y políticos mantenían todavía distintos campos de actuación. GómEZ MolledA, M. ${ }^{a}$ Dolores, La reforma de la España Contemporánea, Madrid, Ed. CSIC, 1966.

3 TuÑón de LARA, Manuel, Medio siglo de cultura española (1885-1936), Madrid, Ed. Tecnos, 1973, pág. 145.

4 TUÑ́́N DE LARA, Manuel, Ibidem. 
actuaron la mayor parte de los intelectuales que tomaron parte en la llegada y configuración de la II República. Fernando de Onís se refiere a Ortega de la siguiente manera: «Puede decirse que con él nace un pensador cuyas ideas (...) radican en lo más central, tanto del problema de Europa como del problema de España... A su alrededor se ha formado un núcleo de jóvenes en cuyo espíritu se entrelazan dos anhelos...poseer la cultura europea y realizar la salvación de España» 5 .

Ahora bien, llegar a la conclusión de que el grupo de intelectuales que tomó protagonismo en la Historia de España durante el primer tercio del siglo xx era homogéneo y compacto sería igualmente un error. Como ya he señalado, las fuentes de las que bebieron y los objetivos generales que deseaban conseguir tuvieron importantes puntos de coincidencia sin embargo la realidad es otra muy distinta. La evolución de posturas, su afinidad ideológica con unos determinados partidos políticos o la toma de posición según las circunstancias históricas, fue completamente diferente. No hay que olvidar que no todos los intelectuales deseaban los mismos grados de transformación de las $\operatorname{cosas}^{6}$ : las ofertas de militancia política iban desde la defensa de la Monarquía, aunque constituida de forma radicalmente diferente, hasta los partidos de la izquierda más pura como era el Socialista, pasando por los republicanos-reformistas, partidos de centro etc.

Realmente la formación del grupo compacto (que no homogéneo) de intelectuales que luchaban por un mismo objetivo no se dio hasta 1930-31 en que la inmensa mayoría aunaron sus fuerzas para traer la República. Pero hasta ese momento, las pautas de comportamiento e ideología seguían unos derroteros muy personales. Por ejemplo, la Generación del 98 (algunos de los cuales estuvieron presentes en el primer Gobierno republicano de 1931) no fue el grupo homogéneo del que tradicionalmente se ha venido hablando: políticamente cada uno de ellos era diferente al resto. Así, mientras Unamuno era republicano, llegando en algún momento a definirse como socialista, Valle-Inclán era de izquierdas pero sin una acción política concreta; Maeztu, durante mucho tiempo, fue el símbolo del antiliberalismo y la antidemocracia, igualmente apoyado por Azorín que más tarde se definiría como republicano. Baroja mantenía una actitud "anarquista" desde el punto de vista de no comprometerse con ninguna opción política, y Machado pasó a ingresar en la Agrupación al Servicio de la República.

En la I Guerra Mundial la mayor parte de los intelectuales fueron aliadófilos: Fernández de los Ríos, Araquistáin, Azaña, Unamuno, Valle-Inclán, Ortega y Gasset... firmaron un manifiesto de adhesión a los aliados. Sin embargo, la Revolución

5 Gómez MolledA, M. ${ }^{a}$ Dolores, op. cita, pág. 492.

6 Según Tuñón de Lara, la evolución o diferente toma de posturas entre los intelectuales podría resumirse de la siguiente manera: a) aquellos que temen la subversión de los valores tradicionales (Ramiro de Maeztu entre ellos), b) los que se muestran críticos con el régimen pero temen las reacciones «violentas» o subversivas (Unamuno, Azaña), c) los críticos con la situación política pero que dan una orientación principalmente educativa a las reformas, y d) aquellos que tienen conciencia del derrumbamiento de los valores y desean su recreación a partir de una nueva base. Vid, TuÑón DE LARA, Manuel, op. cita. 
Rusa tuvo unas valoraciones muy diferentes según las simpatías políticas que cada uno profesase: fueron principalmente aquellos intelectuales más próximos a la izquierda los que defendieron, justificaron y admiraron dicha revolución; y en muchos casos, el hecho de que el régimen primorriverista fuese contra ella "determinó que los elementos intelectuales opuestos al régimen estuviesen en condiciones de ver con ojos benevolentes el sistema político y social instaurado en el otro extremo de Europa, estimulándoles a visitar la Unión Soviética y ofrecer una visión positiva de ella "7, según señala Genoveva G. ${ }^{a}$ Queipo de Llano. En 1919 el PSOE hizo un manifiesto en favor de la Revolución Rusa. No era extraño, por tanto, oír afirmaciones como la de Manuel Cordero: «En el problema cultural, la labor de los rusos ha sido magnífica... Los rusos lo dicen claramente: están creando en la juventud la fuerza del mañana; tras la dictadura de hoy está el porvenir de un pueblo. Esa labor ha costado sangre, es cierto, pero también la costó el absolutismo para no resolver nada» ${ }^{8}$. O la no menos expresiva de Araquistáin: «Pocos hombres habrá que hayan sentido y sientan una admiración tan sincera y profunda por la revolución rusa como yo. Creo que después de la revolución inglesa, de la revolución francesa y de la declaración de independencia de los Estados Unidos, la revolución rusa es el más grande experimento histórico que se ha hecho en el mundo»?.

Durante la Dictadura de Primo de Rivera las posiciones de los intelectuales resultaron igualmente desiguales. El 13 de Septiembre de 1923, no hubo una reacción de condena unánime ante el nuevo régimen. Suárez Cortina recoge el testimonio de Azaña: "Manuel Azaña... manifestó más tarde que la Dictadura fue recibida con un elemento renovador en un sentido manifiestamente liberal con el apoyo de un importante núcleo de la «masa neutra» "10. Figuras como Unamuno, Azaña, Pérez de Ayala o Soriano fueron, junto con la revista «España» o el Ateneo, los principales oponentes del nuevo régimen en 1923; pero Maeztu, Azorín, D'Ors fueron favorables a Primo de Rivera, y Ortega y El Sol e incluso Araquistáin mantuvieron posturas intermedias y expectantes pero nunca de oposición radical.

El mismo Partido Socialista no se opuso en un primer momento a la Dictadura, sino que participó «con» ella y consiguientemente colaboró «con» ella a través de diferentes actitudes y tomas de posición tanto activas como pasivas. Tuñón señala a figuras tan relevantes en el partido como Besteiro, Saborit, Largo Caballero o Trifón Gómez, como responsables de la toma de decisión de no participar en conspiraciones o cualquier otro tipo de oposición contra el poder establecido. De esta forma, en 1924, tanto el PSOE como la UGT decidieron aceptar la prohibición de la celebración de las manifestaciones del Primero de Mayo para permanecer en el marco de la legalidad. Entre ese mismo año y 1926 el Partido Socialista y la

7 García QueIPo de Llano, Genoveva, op. cita, pág. 518.

8 Cordero, Manuel, «¿Existe la crisis de la democracia?», El Socialista, 11 de Febrero de 1930.

9 ARAQUISTAIN, Luis, «Un interesante discurso de Luis Araquistáin», El Socialista, 28 de Junio de 1931.

10 SuÁRez CortinA, Manuel, op. cita, pág. 282. 
UGT tuvieron cargos o representantes en diferentes organismos: Manuel Cordero en el Consejo Interventor de Cuentas, Largo Caballero y Saborit participaron en la Comisión Interina de Corporaciones, Largo Caballero formó parte del Consejo de Estado (1926)... Hasta tal punto el PSOE mantuvo una actitud de lucha por sus propios intereses que, incluso una vez manifestada su oposición a los «continuadores de la Dictadura» (el Gobierno Berenguer), quiso participar en las elecciones a Ayuntamientos y Diputaciones Provinciales desmarcándose «por el momento» de cualquier compromiso o colaboración con otras fuerzas políticas que pudiesen comprometerle: «El Comité Nacional está animado de los mejores deseos de cordialidad con los elementos afines: pero precisamente para que estos deseos puedan tener una cumplida satisfacción, entiende que la exigencia primordial es que cada grupo y cada tendencia se definan lo más claramente posible, respetándonos mutuamente en nuestra propia e independiente esfera de acción.

Pactar uniones o inteligencias prematuras, de más valor aparente que el real, nos parece que, en vez de favorecer, perjudicaría grandemente al triunfo de nuestros propósitos»11.

No es extraño pues que, el mismo año en que el Partido Socialista ya había comenzado a definirse contrario al régimen de Primo de Rivera y del Gobierno Berenguer, se realizaran afirmaciones tan expresivas como la de Ossorio y Gallardo que, expuesto lo anterior, hacen innecesaria cualquier explicación. Ante la celebración de las elecciones arriba mencionadas Ossorio y Gallardo manifestaba: “¿Cómo se van a hacer las elecciones (...) si no hay más organización que la U.P. y el Partido Socialista?»12.

De cualquier forma, y según señala Genoveva G. ${ }^{a}$ Queipo de Llano, a excepción de casos muy representativos como los señalados anteriormente de Unamuno, Azaña, Azorín, Maeztu etc. (quienes tomaron posiciones político-ideológicas de forma casi inmediata) por lo general no fue hasta 1928 cuando los intelectuales se situaron de una forma absolutamente definida contra la Dictadura. El movimiento estudiantil de 1929 fue clave en figuras como Azorín u Ortega que evolucionaron indefectiblemente contra el régimen. El Partido Socialista fue más lento e independiente a la hora de alinearse en un grupo concreto (a excepción de Fernando de los Ríos, Jiménez de Asúa, Álvarez del Vayo, e Indalecio Prieto), pero finalmente pasó a engrosar el sector de aquellos que, tanto por unos utópicos deseos de reforma, como por enemistad u oposición contra la Dictadura y la Monarquía de Alfonso XIII, fueron los constituidores de un ambicioso proyecto político, social, y cultural: la II República.

En 1931, como Aubert, Becaraud y López Campillo coinciden en señalar, estuvieron presentes intelectuales de la Generación del 98, del 14 y del 27. Todos

11 «El Partido Socialista define su actitud política», Nota del Comité Nacional: Andrés Saborit, secretario; Julián Besteiro, Presidente, El Socialista, 23 de Febrero de 1930.

12 "Conferencia de Ossorio y Gallardo», El Socialista, 6 de Febrero de 1930. 
ellos con visiones diferentes para los mismo problemas, con la conciencia de ser imprescindibles en la creación del nuevo Estado Español, con la necesidad de llevar a la práctica todo un pensamiento que habían ido fraguando a través de su propia formación y del estudio, pero significativamente nunca a través de la experiencia. No eran ciertamente una clase política «profesional» sino que, ante la falta de políticos en los dos partidos más decisivos (republicano y socialista), ocuparon unos puestos que en 1933 fueron «devueltos» a aquellos que estaban dedicados y preparados exclusivamente para la política.

La masiva llegada de intelectuales al ámbito político, bien desde la oposición a la Monarquía, a la que presionaron a través de diferentes medios y actuaciones, bien desde el mismo Gobierno, determinó que el régimen instituido en 1931 fuese denominado como la «República de los profesores o de los intelectuales». En el caso de las presiones ejercidas desde la oposición no hay que olvidar que, durante el último año de la Dictadura y de la Monarquía, la oposición a ambos regímenes alcanzó su cenit, acaparando la intelectualidad la mayor parte del protagonismo. Becaraud y López Campillo citan como actos relevantes de lucha la "Carta al Dictador» (1930) firmada por 170 intelectuales entre los que estaban Ortega, Marañón, Zulueta, Pérez de Ayala, Jiménez de Asúa etc.; el discurso de Prieto en el Ateneo contra la Dictadura y la Monarquía (25 de Abril de 1930); el 2 de Mayo el ataque de Unamuno en una conferencia a la Monarquía y el 31 de Mayo la declaración de Alcalá Zamora como «Republicano conservador» ${ }^{13}$... Centros como el Ateneo, la Casa del Pueblo o la Residencia de Estudiantes; prensa como El Socialista, El Espectador, El Sol, La Revista de Occidente etc., se enfrentaron directamente a ambos regímenes a la par que apoyaban la venida del republicano. Si a esto sumamos las movilizaciones estudiantiles, el Pacto de San Sebastián, la Agrupación al Servicio de la República o la Sublevación de Jaca, tenemos muestras más que evidentes de que el régimen monárquico no era compatible con los intelectualespolíticos y que estaba abocado a la desaparición.

Por otra parte, la denominación de «República de intelectuales» queda de sobra justificada si tenemos en cuenta que las Cortes de 1931 estuvieron formadas por una clara mayoría intelectual y de clases medias entre los que se encontraban 50 profesores, 123 abogados, 30 periodistas, 41 médicos, 6 farmacéuticos y 8 profesores. Los principales intelectuales que formaron parte del Gobierno Provisional y Primer Bienio quedarían reflejados según su preparación y actividad profesional de la siguiente manera:

13 Becaraud, Jean y López Campillo, Evelyne, Los intelectuales españoles durante la II República, Madrid, Ed. Siglo XXI, 1978, págs. 14-15. 
El papel de los intelectuales en la gestación de la II República Española. Intelectuales...

\begin{tabular}{|l|l|}
\hline Miembros del Gobierno & Preparación académica y/o profesional \\
\hline Alcalá Zamora & Letrado del Consejo de Estado \\
\hline A. Albornoz & Abogado \\
\hline M. Azaña & Funcionario del Ministerio \\
\hline Carner & Abogado \\
\hline J. Besteiro & Catedrático \\
\hline Casares Quiroga & Abogado. Periodista \\
\hline N. D’Olwer & Profesor \\
\hline M. Domingo & Maestro \\
\hline J. Giral & Catedrático de Universidad \\
\hline Jiménez de Asúa & Catedrático-abogado \\
\hline Lerroux & Periodista \\
\hline M. Maura & Abogado \\
\hline F. de los Ríos & Catedrático de Universidad \\
\hline I. Prieto & Abogado \\
\hline L. Zulueta & Profesor \\
\hline
\end{tabular}

Principales intelectuales y su formación académica. Gobierno provisional y primer bienio republicano

Si además añadimos la presencia constante como «grupos de presión», según los denomina Manuel Ramírez, de diversas asociaciones de profesionales como la Unión Nacional de Abogados (1931), la Unión Farmacéutica Nacional, la Federación Católica de Maestros Españoles etc., nos encontramos con que, efectivamente, los intelectuales entraron de lleno en la labor de regir y orientar la vida española llevando a cabo una monopolización del poder.

Los objetivos políticos, económicos, culturales y sociales que deseaban conseguir fueron diversos dependiendo de las ideologías o propuestas particulares o de los diferentes partidos. En un primer momento, dichos objetivos parecían estar aunados en uno sólo: conseguir la implantación de la II República como sinónimo de régimen liberal y democrático. A partir de ahí, las demás cuestiones irían siendo solventadas gradualmente ${ }^{14}$. Objetivos como la organización del Consejo de Instrucción Pública, la supresión de la obligatoriedad de la enseñanza religiosa, la creación de Misiones Pedagógicas y escuelas, son buena prueba de que la generación de políticos que en 1931 ocuparon el poder, eran herederos indiscutibles o represen-

14 Según señala Paul Aubert, la concepción del nuevo Estado se basaba principalmente en la descentralización, la creación de un programa de educación, una política social, la idea de la patria como una entidad moral superior y un pueblo soberano. AUBERT, Paul, «Intelectuales y cambio político», Vid., en V.V.A.A. Los orígenes culturales de la II República, op. cita., págs. 169-231. 
tantes de diferentes formas del pensamiento intelectual liberal, bien del Krausismo, de la ILE, o de las Generaciones del 14 y 27. De cualquier forma, y a pesar de todo, hay que señalar que «la obra que simbolizó... la actuación de los intelectuales de la República, más que la reforma agraria o la reforma del ejército, fue esa labor pedagógica de reorganización y desarrollo de la enseñanza pública» ${ }^{15}$. Eran los sectores más destacados, más profesionales y mejor preparados (aunque no siempre en materia política) de la sociedad española del primer tercio del siglo XX.

Ahora bien, si queremos acercarnos al estudio de los principios que fueron defendidos, las acciones que se llevaron a cabo para su consecución y la evolución seguida en cada momento de acuerdo con las circunstancias por los grupos intelectuales durante el período 1930-31, es necesario acudir al análisis particular de cada partido político, colectivo u organización existente a las que la mayoría de los intelectuales pertenecían.

En el caso de los intelectuales socialistas, su actuación durante este período pre y republicano fue clave para que el Partido Socialista se consagrara como una de las mayores fuerzas políticas de España. A pesar del importante peso que desde finales del siglo XIX y primer tercio del Xx habían tenido los sectores de la inteligencia en España, el PSOE siempre se mantuvo en una actitud claramente hostil a la afiliación y por supuesto, a la participación activa de intelectuales en la política del partido. La orientación claramente obrerista y en muchos casos también anti-intelectual se impuso durante buena parte de la trayectoria del partido. Realmente, la afiliación y ostentación de cargos políticos de forma verdaderamente numerosa no se produjo hasta las vísperas de la II República, cuando ésta podía ya adivinarse.

Sin embargo, durante los períodos anteriores, tanto los miembros de base como la Ejecutiva del PSOE se resistieron una y otra vez a dar entrada a todo aquel que no fuera un obrero manual, pues se los identificaba con la burguesía a la que debían combatir. En estos primeros años, que corresponderían aproximadamente a los comprendidos entre 1898 (en que se fundó el Partido) y la I Guerra Mundial (fecha en que Gómez Molleda señala la vuelta de la inteligencia ${ }^{16}$ ), podría afirmarse que la ausencia de los intelectuales fue prácticamente total a excepción de casos muy puntuales como el de Jaime Vera. Un intelectual era inmediatamente asimilado a "una clase media menesterosa y, por lo tanto, acobardada... tímidas y retraídas de los movimientos de renovación profunda ${ }^{17}$ o a "unos señoritos que matan sus ocios manchando cuadros y pergeñando versitos (...) emancipados de toda carrera útil por el dinero de papá... gozan del privilegio de vi-

15 Becaraud, Jean y López Campillo, Evelyne, op. cita, pág. 38.

$16 \mathrm{M}^{\text {a }}$ Dolores Gómez Molleda señala cuatro etapas principales en la evolución de los intelectuales en relación con el Partido Socialista. Para la autora, la I Guerra Mundial marca la «reconciliación» a través del acercamiento de la intelectualidad-partido en acontecimientos claves como los manifiestos aliadófilos, la Revolución Rusa, los sucesos de Agosto de 1917... en que ambos sectores mantuvieron posturas muy afines e iniciaron un creciente proceso de colaboración. GómEz MolLEDA, M. ${ }^{2}$ Dolores, Los reformadores de la España Contemporánea, op. cita.

17 ARAQUistain, Luis, «Los intelectuales españoles y el Socialismo», "España”, 6 de Marzo de 1920. 
vir sin trabajar»18. La confirmación de estas teorías vendrían indudablemente de la mano de Ramiro de Maeztu que, en 1904, ya señalaba que "¿No consiste precisamente el mérito de Pablo Iglesias en que repite el mismo discurso donde quiera que va?... Es verdad que semejante monotonía aburre a los elementos intelectuales. ¿Pero qué importa este aburrimiento ante el socialismo militante? "19; o el mismo Besteiro que "culpaba» a los intelectuales de haber sido la causa del tradicional rechazo que generaban en el Partido «(al) inventar un Socialismo personal, arbitrario e inexistente» 20 .

Las causas de la incorporación de los intelectuales al Partido Socialista estuvieron indiscutiblemente relacionadas con la necesidad de asentar el movimiento socialista y unificar todas las fuerzas a través de símbolos o aspectos externos. La lucha de los intelectuales por entrar en la actividad política del PSOE fue muchas veces polémica: la Escuela Nueva trató de ser el «trampolín» a partir del cual se lanzaran al escenario político del Partido distintos intelectuales, pero se negó una alianza directa con éste en un primer momento. No fue hasta 1912 cuando le fue permitido participar en el IX Congreso del Partido y sólo en 1915, en el X Congreso, se manifestó que "la Escuela Nueva es y será socialista»"21. Hasta entonces, los apoyos y colaboraciones de socialistas como Ovejero, Besteiro, Araquistáin o Jaime Vera se produjeron al margen del Partido Socialista a modo de actividades individuales que tenían su origen, en la mayor parte de los casos, en el espíritu reformista de la ILE de la que muchos de ellos procedían ${ }^{22}$ y que tan poco gustó a los «veteranos del movimiento obrero», según los calificaba Saborit.

La gran explosión de entrada de intelectuales en el PSOE se produjo en los años comprendidos entre 1909-1915, en que se afiliaron figuras de la categoría de Andrés Ovejero, Luis Araquistáin, Julián Besteiro (1915), Álvarez del Vayo y Fernando de los Ríos (1919), aunque ya venían colaborando en las distintas empresas como simpatizantes socialistas desde tiempo atrás. Como ya he mencionado, el $\mathrm{X}$ Congreso del Partido (1915) tuvo ya una importante representación intelectual,

18 LOZANO, Luis, «El señoritismo en acción. Avanzados en arte; en política retardatarios», "Nosotros", n. ${ }^{\circ}$ 30, 20 de Noviembre de 1930. Ctr. por Paul Aubert en «Intelectuales y cambio político», Vid., en V.V.A.A. Los orígenes culturales de la II República, op. cita, págs. 36-37. El autor señala, junto con el artículo de Luis Lozano, otros testimonios que ponen de manifiesto las serias reticencias de los sectores obreros a la incorporación de los intelectuales al ámbito de la política.

19 MAezTu, Ramiro de, «Pablo Iglesias», "España”, 28 de Agosto de 1904.

20 Gómez Molleda, M. ${ }^{a}$ Dolores $_{\Perp}$ El Socialismo español y los intelectuales, Salamanca, Ed. Universidad de Salamanca, 1980, pág. 13.

21 El Socialista, 25 de Octubre de 1915, Ctr. por Tuñón de Lara en Medio siglo de cultura española (1885-1936), op. cita, pág. 174.

22 La Escuela Nueva se fundó bajo el espíritu de difundir la cultura y el saber entre los sectores proletarios. Pero desde un primer momento estuvo inspirada en el carácter reformista de Giner y de la ILE, movida por un liberalismo que contradecía los más mínimos principios del Socialismo del momento. Los intelectuales de esta primera década del siglo XX eran los representantes de la opción política republicano-socialista, muy próximos al laborismo inglés; defensores del colaboracionismo a excepción de etapas de crisis en que, según Gómez Molleda, defendían utopías revolucionarias. En cualquier caso, este pensamiento era absolutamente incompatible con la disciplina propugnada por el PSOE en este momento. Vid. Villacorta Baños, Francisco, Burguesía y cultura. Los intelectuales españoles en la sociedad liberal 1808-1931, Madrid, Ed. Siglo XXI, 1980. 
«hecho insólito» en un grupo político tan marcado por el obrerismo, según ha señalado Tuñón de Lara. Sin embargo, podemos observar un fenómeno curioso: en 1913 se fundó la Liga de Educación Política donde participaron Araquistáin y Fernando de los Ríos (junto con Azaña, Madariaga, Ortega, Zulueta...) independientemente de su tendencia política; en 1915 se publicó el manifiesto aliadófilo donde firmarían Fernando de los Ríos y Araquistáin al lado de figuras de la política y de la cultura como Pérez Galdós, Azaña, Zulueta, Zuloaga, Rusiñol, Marañón...; los primeros días del Gobierno Berenguer, los intelectuales apoyaron los movimientos estudiantiles: Jiménez de Asúa, simpatizante del PSOE y afiliado al Partido un año más tarde, tomó parte a nivel individual; el 25 de abril de 1930 Indalecio Prieto ofreció el ya mencionado discurso en el Ateneo contra la Dictadura y contra la Monarquía, y en 1931, con motivo de la clausura de la Universidad durante unos días, Ovejero, Besteiro, y Jiménez de Asúa colaboraron con «universidades» improvisadas, pero todas estas intervenciones nunca las hicieron como miembros del $\mathrm{PSOE}^{23}$. Es decir, hay un lento proceso a la hora de aceptar la necesidad de incorporar a parte de la intelectualidad española al partido como grupo rector ideológico y «espiritual» del mismo.

A pesar del impulso práctico y las resoluciones activas que proporcionaba la masa general de los miembros socialistas, era evidente que las nuevas condiciones históricas imponían la necesidad de un pensamiento rector que dirigiera la acción y proyectara la ideología del partido hacia ámbitos sociales hasta entonces ajenos al Socialismo pero que podían convertirse indiscutiblemente en una importante fuerza potencial para el PSOE. Luis Araquistáin achacó a la falta de intelectuales el que el partido no se convirtiera en un poderoso movimiento: «Han faltado hombres capaces de atraerse y asimilarse, por la vía del pensamiento, las masas anarquistas y republicanas de España» ${ }^{24}$.

Realmente no fue hasta la segunda década del siglo, y de forma incuestionable en «vísperas» de la II República, cuando el intelectual comenzó a desempeñar un papel verdaderamente reconocido en el Partido: son los años de definición del PSOE como gran fuerza política pura frente a la decadencia de los partidos dinásticos, así como de anuncio del relevante papel que podían desempeñar en un futuro no muy lejano como una de las más importantes fuerzas políticas del país. Es por tanto a partir de este momento, cuando los intelectuales comenzaron a tomar parte activa en la estrategia del Partido.

23 Sobre esta intervención de Indalecio Prieto en la primavera de 1930 Santos Juliá señala como, frente a otros líderes que intervinieron con discursos en centros específicamente o al menos con un fuerte contenido político, Prieto lo hizo en un lugar no vinculado al PSOE y con una gran tradición en la vida cultural e intelectual española: el Ateneo. Además, el autor destaca la acogida de sus palabras e ideas: "Los socialistas, pues, como tantos madrileños del momento, se definen y si Negrín lo había hecho todavía en un lugar cerrado, ante el reducido auditorio de la Casa del Pueblo, Largo lo hace ya al aire libre, ante el mausoleo de Iglesias, Prieto lo hará en un espacio no propiamente socialista, el Ateneo, y ante un público bullicioso que no cabe en el salón y los pasillos y que se desparrama por las calles adyacentes" (JuLIÁ, Santos, «De cómo Madrid se volvió republicano», Vid en VVAA, Los orígenes culturales de la II República, Madrid, Ed. Siglo XXI, pág. 350).

24 Gómez MolledA, M. a Dolores, El Socialismo español y los intelectuales, op. cita, Págs. 99-100. 


\begin{tabular}{|c|c|c|c|}
\hline Intelectual & $\begin{array}{l}\text { Formación } \\
\text { y actividad profesional }\end{array}$ & Cargo/s 1931-33 & $\begin{array}{l}\text { Fecha } \\
\text { afiliación } \\
\text { PSOE }\end{array}$ \\
\hline Julio Álvarez del Vayo & $\begin{array}{l}\text { Corresponsal de prensa internacio- } \\
\text { nal en La Nación } n^{25} \text {. }\end{array}$ & $\begin{array}{l}1931 \text { Embajador } \\
\text { en México. }\end{array}$ & 1911 \\
\hline Luis Araquistáin & $\begin{array}{l}\text { Escritor y creador teatral. Director } \\
\text { de revistas «España» y «Leviatán». } \\
\text { Colaborador en periódicos. }\end{array}$ & $\begin{array}{l}\text { Subsecretario } \\
\text { del Ministerio } \\
\text { de Trabajo. }\end{array}$ & $\begin{array}{l}1914 / \\
1929\end{array}$ \\
\hline Julián Besteiro & $\begin{array}{l}\text { Educado en la I. L. E. Catedrático } \\
\text { de Instituto. Doctor y Catedrático } \\
\text { de Lógica. Miembro Academia de } \\
\text { Ciencias Morales y Políticas. }\end{array}$ & $\begin{array}{l}\text { 1931-33 Presi- } \\
\text { dente de las } \\
\text { Cortes. } \\
1932 \text { Presidente } \\
\text { Comisión Ejecu- } \\
\text { tiva UGT }\end{array}$ & 1912 \\
\hline Manuel Cordero & $\begin{array}{l}\text { Profesor en el Sindicato de Artes } \\
\text { Blancas. Colaborador periodístico. }\end{array}$ & $\begin{array}{l}1932 \text { Presidente } \\
\text { UGT }\end{array}$ & 1905 \\
\hline Luis Jiménez de Asúa & $\begin{array}{l}\text { Contactos con la Residencia de } \\
\text { Estudiantes. Catedrático de Dere- } \\
\text { cho Penal } \\
\text { Director del Instituto de Estudios } \\
\text { Penales }\end{array}$ & $\begin{array}{l}1931 \text { Presidente } \\
\text { de la Comisión } \\
\text { Constitucional. } \\
1932 \text { Miembro } \\
\text { de la Comisión } \\
\text { redactora del } \\
\text { Código Penal. }\end{array}$ & 1931 \\
\hline Fernando de los Ríos & $\begin{array}{l}\text { Alumno y profesor en la I. L. E. } \\
\text { Beca de investigación en Alemania. } \\
\text { Doctor y catedrático de Derecho } \\
\text { en la Universidad de Granada. }\end{array}$ & $\begin{array}{l}1931 \text { Ministro de } \\
\text { Justicia (Gobier- } \\
\text { no Provisional). } \\
\text { 1931-33 Ministro } \\
\text { de Instrucción } \\
\text { Pública y Estado }\end{array}$ & 1919 \\
\hline Rodolfo LLopis & $\begin{array}{l}\text { Maestro Nacional y profesor en } \\
\text { la Escuela Normal de Cuenca. } \\
\text { Admirador de la ILE }\end{array}$ & $\begin{array}{l}\text { Director de Prime- } \\
\text { ra Enseñanza } \\
\text { durante el Primer } \\
\text { Gobierno Provi- } \\
\text { sional y el Gobier- } \\
\text { no de } 1931-33\end{array}$ & 1919 \\
\hline Andrés Ovejero & $\begin{array}{l}\text { Contactos con la Residencia de } \\
\text { Estudiantes. Catedrático de Teoría } \\
\text { de la Literatura y de las Artes. } \\
\text { Colaborador periodístico. } \\
\text { Miembro Academia de Bellas Artes } \\
\text { de San Fernando }\end{array}$ & & 1914 \\
\hline Indalecio Prieto & Periodista & $\begin{array}{l}\text { 1931-33 Ministro } \\
\text { de Obras Públicas }\end{array}$ & 1899 \\
\hline Julián Zugazagoitia & $\begin{array}{l}\text { Periodista. Director de El Socialista. } \\
\text { Escritor enclavado en la novela } \\
\text { social comprometida de los años } \\
\text { treinta. }\end{array}$ & $\begin{array}{l}\text { Diputado en las } \\
\text { Cortes del } \\
\text { Gobierno Provi- } \\
\text { sional y en el de } \\
1931-33 .\end{array}$ & 1914 \\
\hline
\end{tabular}

Cuadro de relacion de formación-profesiones-pincipales cargos políticos en 1931

${ }^{25}$ Diario de Buenos Aires donde realizó sus principales crónicas políticas. 
Si seguimos el diario portavoz de dicho grupo político, El Socialista, podemos observar que en los años 1930-1931 la participación y colaboración de los intelectuales en diferentes ámbitos de la vida pública se incrementó considerablemente, teniendo además un eco mayor en aquellos medios de comunicación que más influencia social ejercían. Se inició toda una campaña de defensa de la labor pública que el sector intelectual podía y de hecho estaba ya realizando. El Socialista elogiaba y ensalzaba las actuaciones de la intelectualidad destacando siempre la gran acogida que en los distintos ámbitos culturales, políticos y sociales se les estaba dispensando. No es extraño encontrar en los titulares, y de forma destacada, los nombres de aquellos intelectuales que, ya fuesen de una u otra ideología, habían tomado parte activa en favor del futuro régimen republicano. Tenemos cabeceras tan significativas como: "Propaganda socialista. La conferencia de Cordero en Burgos» (27 de Febrero de 1930), "Lo que dicen los camaradas Besteiro, Saborit, Caballero y Fernando de los Ríos" (24 de Febrero de 1931), o «Documento importantísimo. Marañón, Ortega y Gasset, Unamuno, Alomar y otros intelectuales ratifican su adhesión al Gobierno de la República» (14 de Mayo de 1931$)^{26}$.

Igualmente, las introducciones y comentarios a este tipo de artículos exaltaban y valoraban en un alto grado cada comparecencia, reflexión y actitud del intelectual, a la vez que destacaban cuidadosamente la buena acogida e incluso el entusiasmo del público que asistía a los actos. A diferencia de manifiestos, proclamas, cartas o algún otro tipo de documento que era publicado manteniendo su integridad absoluta, y sin ningún tipo de comentario o explicación por parte de la editorial, estas comparecencias públicas de los intelectuales eran cuidadosamente analizadas, destacándose aquellos aspectos más relevantes tanto del disertador como del discurso. Así, podemos encontrar puntualizaciones tan expresivas como: «El domingo por la mañana (...) se celebró el primer acto público de la Liga Nacional Laica.

La entrada fue por rigurosa invitación, no obstante lo cual, a la hora de comenzar el mitin el teatro presentaba un aspecto imponente con todas las localidades ocupadas y numeroso público aglomerado en los pasillos y puertas de entrada. Asisten numerosísimas damas" ${ }^{27}$.

Otro buen ejemplo, de entre los muchos de cómo el periódico favorecía e impulsaba la labor de los intelectuales valorando al máximo sus actividades, podría

26 Todos los titulares arriba citados corresponden al diario El Socialista.

27 «Importantísimo mitin de la Liga Laica», El Socialista, 4 de Noviembre de 1930. En este acto participaron Antonio Fernández Quer, Victoria Kent, y Álvaro de Albornoz. Es muy probable que la presencia de la segunda congregara el importante número de mujeres al que se alude, en cualquier caso es curioso observar como el periódico destaca y valora en grado sumo la comparecencia de éstas como se destaca igualmente en el siguiente artículo. La incorporación de la mujer a los progresos y derechos sociales, defendidos entre otras por Clara Campoamor, Victoria Kent, María de Lluria (colaboradora de este diario) y un número cada vez más importante de políticos, venía anunciándose y destacándose desde ámbitos muy diferentes. 
ser el siguiente: "Ayer tarde ocupó una vez más la tribuna de la Casa del Pueblo nuestro querido compañero Julián Besteiro, quien en el anunciado acto, organizado por el Sindicato de las Artes Blancas, disertó acerca de "La clase obrera y la organización del trabajo intelectual». El teatro se hallaba completamente ocupado por trabajadores, entre los que se advertía la presencia de un gran número de señoras y señoritas" 28 . Si analizamos esta breve introducción a la actuación intelectual, observamos la presencia de datos importantísimos: el tratamiento de «querido compañero" con el que eran aludidos todos aquellos afiliados, simpatizantes o colaboradores del Partido Socialista, y que indudablemente servía como elemento «identificador» de la persona; se destacaba el Sindicato organizador del acto, así como la presencia importantísima de trabajadores. De esta forma se ponía de manifiesto el sector interesado al que iba dirigida la conferencia, el cual no había sido tradicionalmente afín a la labor de la intelectualidad.

El diario El Socialista no dejaba pasar aquellas ocasiones en que podía ofrecer a sus lectores una definición del término «intelectual», explicar sus funciones culturales, sociales y políticas, delimitar sus campos de actuación, su cada vez más necesaria presencia en el Partido Socialista y en la política en general. Es decir, se ofrecía la «definición» de aquello que hasta entonces había pertenecido al ámbito de lo marginado y desconocido para los más puros militantes del PSOE. En muchos casos iban a ser los mismos intelectuales los que, de una forma comprometida y entusiasta, delimitarían y aclararían cuales eran sus compromisos y funciones a desempeñar desde su condición de intelectualidad. Para Jaime Quintanilla, las diferencias entre obreros e intelectuales no eran muchas: definía a los dos como asalariados y por lo tanto explotados por el sistema capitalista, ambos debían luchar por llevar a cabo una revolución útili29; para Luis de Brouckere o Gregorio Marañón, eran los creadores de la nueva España a través de la preparación del pueblo en la cultura general y en la cultura política ${ }^{30}$; Luis Araquistáin los desligaba del concepto de «señoritos» y parásitos sociales afirmando que «...trabajador es también el que ejerce una función predominantemente intelectual, el hombre de ciencia, el artista, el inventor, el técnico y el organizador de un Sindicato o de una industria. Trabajadores son todos aquellos que prestan un servicio social que la sociedad necesita... ${ }^{31}$.

28 «Interesante conferencia de Besteiro», El Socialista, 15 de Marzo de 1930.

29 QUINTANILLA, Jaime, «Cuestiones doctrinales. Intelectuales y obreros», El Socialista, 19 de Marzo de 1930. La definición del intelectual como obrero fue defendida en más de una ocasión en las páginas de este diario. El 20 de Abril de 1930, Javier Bueno en «El Socialismo y los intelectuales» se refería al «intelectual obrero» como aquél cuyo trabajo tenía como secundario el muscular. Este tipo de definiciones, en que trataban de aproximar conceptos hasta entonces enfrentados, correspondían a parte de la dinámica en la que había entrado el PSOE de asimilar a la intelectualidad como parte imprescindible de un partido tradicionalmente obrero.

30 Brouckere, Luis de, «Algunas dudas a modo de conclusión», El Socialista, 8 de Abril de 1930.

MARAÑón, Gregorio, «Socialismo, inteligencia y civilidad», El Socialista 19 de Febrero de 1930.

31 «Texto taquigráfico del bello discurso de Luis Araquistáin», El Socialista, 18 de Septiembre de 1931. 
Pero al igual que desde este diario ${ }^{32}$ se intentaba mejorar el concepto que del intelectual se pudiera tener y se defendía sus diferentes actuaciones en el ámbito público, también se exhortaba a la necesidad de la intervención de unos cuadros intelectuales convenientemente preparados en la actividad política. Así, a lo largo de los años 1930-31, encontramos en El Socialista diferentes reflexiones acerca de la figura del intelectual como educador y formador del pueblo ${ }^{33}$, como miembros del Partido Socialista (tema que no dejó de suscitar cierta tensión, como ya he señalado anteriormente, y que requería la previa aceptación por parte de los nuevos miembros de someterse a los dictados del Partido), y de como su labor política podía resultar de una validez enorme. Es muy representativa la siguiente disquisición sobre el ingreso de uno de los que serían los intelectuales más representativos del Socialismo de este momento: «Sus ataques a la dictadura le declararon republicano ferviente. Sus conferencias en la Casa del Pueblo, nuestra Casa, nos le declararon socialista sin rebozo...

Sin embargo el verdadero Jiménez Asúa no está en el mundo político. A Jiménez de Asúa solamente se le encuentra en la Universidad...

En cuanto a su tarea en el Partido, nada queremos decir. Todo su valor personal se va diluyendo gota a gota en la organización, en un trabajo continuo, atento, disciplinado. Esa disciplina nuestra, de valor tan grande, que nos envidian y desean para sí los demás partidos» 34 .

Junto a este artículo tenemos en El Socialista, un testimonio que no haría sino poner de manifiesto la polémica existente entre la aceptación y el rechazo de la intelectualidad en el Partido. Es el artículo «Conferencia de don Luis Jiménez de Asúa», pronunciada casi un año antes de su ingreso en el PSOE, y donde él mismo dudaba curiosamente de la validez de la labor del intelectual (22 de Febrero de 1930).

También fueron objeto de reflexión la pertinencia o no de la aceptación de cargos políticos por parte de los intelectuales. Se definieron y especificaron los límites y características de esta nueva actividad que debían desempeñar aquellos sectores que, de una forma tan llamativa e incluso para ciertos grupos alarmante, se estaban incorporando al partido. A este respecto, ya Luis Araquistáin en 1920 hizo

32 El Socialista era un diario de proyección ideológico-propagandística, dirigido a sectores concretos entre los que se encontraría el obrero, a quien se trataba de inculcar un determinado nivel de formación.

${ }^{33}$ La campaña del «intelectual como educador» es importantísima en El Socialista. Encontramos sobre el tema artículos como «Socialismo, inteligencia y civilidad» de Gregorio Marañón (10 de Febrero de 1930), «Interesante conferencia de Besteiro» (15 de Marzo de 1930), Julián Besteiro «Hacia la libertad y la democracia» (8 de Mayo de 1930), «Pronunciaron interesantes discursos Regina García, Manuel Cordero y Andrés Ovejero» (12 de Septiembre de 1930), etc.

34 Serrano Ponoela?, «Jiménez de Asúa, militante nuevo, pero socialista antiguo», El Socialista, 12 de Diciembre de 1931. Si analizamos este artículo observaremos que son destacados como elementos de gran relevancia la organización, disciplina, y fidelidad, exigidos a cualquier militante del PSOE. Estas cualidades parecen ser muy valoradas por el mismo Jiménez de Asúa para matizar, de alguna forma, su condición de intelectual «independiente», reticente hasta un tiempo no muy lejano a acatar la disciplina que requiere cualquier partido. 
una reflexión que cambiaría años más tarde acerca de la necesidad de que los intelectuales no actuasen individualmente en la política, es decir: no asumiesen cargos políticos aunque sí interviniesen a través de organizaciones, asociaciones etc. ${ }^{35}$ En 1930-31 la división de opiniones continuaba: mientras Jiménez de Asúa rechazaba cualquier similitud entre la labor del político y del intelectual («Establece las diferencias entre el intelectual y el político, diciendo que mientras aquél es absorbido por leyes permanentes, éste tiene que captar la realidad fugitiva. Uno y otro pueden servir y engrandecer a la patria desde su sitio») ${ }^{36}$, Luis Araquistáin curiosamente afirmaba que: "Sólo un Estado espléndido puede atraer a sus funciones a los hombres más preparados y de mejor iniciativa ${ }^{37}$.

De cualquier forma, a medida que se evolucionaba hacia una certeza absoluta sobre la imparable llegada de la República, las posiciones se unificaron hacia la defensa de la necesidad del grupo intelectual en la política.

Las continuas afirmaciones en los distintos ámbitos del Partido Socialista, incluso fuera de él, de que profesionales médicos, abogados, profesores... estaban afiliándose en números verdaderamente significativos provocaron un auténtico «fenómeno social» dentro del Partido. Como acabamos de ver, una inmensa maquinaria se puso en funcionamiento para controlar y dar cabida a los nuevos acontecimientos que estaban sucediendo. A partir de este momento el «...heterogéneo mundo intelectual tenía el rasgo común de la rebeldía, de la falta de conformidad con lo establecido. Esta tendencia se manifestó a veces en el orden puramente formal, otras en la revisión de conceptos, y algunas, en fin, en una actitud que, trascendiendo el plano cultural, penetró en el de las ideas y el comportamiento político»38.

Pero esta admisión en el mundo de la política no se hizo de forma gratuita: a todos y cada uno de ellos se les exigió disciplina y fidelidad para con los principios y programa del Partido, teniendo que renunciar muchas veces a criterios o deseos de actuación individualizada. Los intelectuales dentro del Partido y con cargo políticos tuvieron que limitar sus palabras o acciones a las oficialmente dictadas, lo que originó más de un desencuentro con la dictadura y el PSOE en general en más de una ocasión. Si la unión de acción y pensamiento no hubieran sido prioritarios en este momento, prensa socialista y Partido habrían dejado entrever más de una diferencia de opinión entre los intelectuales y la Ejecutiva Socialista.

\footnotetext{
35 ARAQUISTAIN, Luis, «Los escritores y la política», "España”,10 de Abril de 1920.

36 «Importantes discursos del ministro, del catedrático Jiménez de Asúa y de un estudiante de la F.U.E.», El Socialista, 20 de Octubre de 1931).

37 ARAquistain, Luis, «Un Estado fuerte. Perfiles de la República», El Socialista, 11 de Noviembre de 1931. La trayectoria de Araquistáin en la aceptación de los intelectuales en puestos políticos fue gradual y así, si en 1920, no era partidario de esta política y en 1931, como hemos visto, consideraba su presencia como símbolo de un Estado fuerte, en 1930 en el mismo diario El Socialista acusaba a este grupo social de haber estado al servicio de la burguesía durante la Dictadura de Primo de Rivera. («Comentario a un ligero comentario", El Socialista, 9 de Enero de 1930).

38 TUÑ́́n DE LARA, Manuel, La España del siglo XX. La quiebra de una forma de Estado (1898-1931), Barcelona, Ed. Laia, pág. 230.
} 
Sin embargo, lo que primó por encima de todo en los años 1930-31, e incluso hasta 1933 (aunque en menor medida), fue la unidad de acción dentro del Partido, la «renuncia» a muchas intervenciones y acciones de carácter individual por parte de los intelectuales, y la entrega al servicio del PSOE y la República de todo un pensamiento de élite definido por el reformismo y la modernidad. Los intelectuales socialistas se convirtieron en parte decisiva de aquellos que, como Paul Aubert señala, se identificaron, constituyeron e intervinieron en el régimen inaugurado el 14 de Abril de 1931. Según he señalado anteriormente, durante el período 1930-31 los intelectuales socialistas se aunaron bajo un proyecto político común y bajo una disciplina de partido; las medidas y las formas para llevarlas a cabo variaron de unos a otros, pero todos participaron del único deseo de que la II República llegara a buen término y de que el PSOE consiguiera por primera vez en su Historia llegar al poder.

Pero una vez los intelectuales llegaron al poder, los factores que ya he mencionado con anterioridad de diversidad de procedencias y por tanto de ideologías, y la falta de una experiencia política que diese a todos los proyectos un espíritu práctico, determinó la lucha interna del sector político-intelectual y la decepción de muchos. Según Marichal, muchos llegaron a la conclusión de que la política destruía a las personas aunque cambiase la sociedad. 